\title{
Factors Affecting Interpersonal Competence of Nursing Students: Focused on Self-Assertiveness and Empathy
}

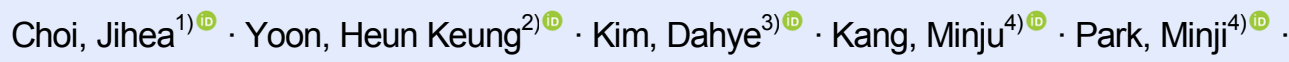

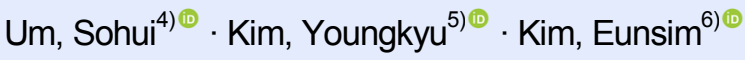

\begin{abstract}
1) Associate Professor, Department of Nursing, Yonsei University Wonju College of Medicine, Wonju
2) Research Fellow, Department of Nursing, Yonsei University Wonju College of Medicine, Wonju

3) Clinical Nurse, Boeun Nursing Home, Wonju

4) Clinical Nurse, Department of Nursing, Yonsei University Medical Center, Seoul

5) Clinical Nurse, Department of Health Care Policy, Public Health Center, Siheung

6) Clinical Research Associate, IVQIA, Seoul, Korea
\end{abstract}

\begin{abstract}
Purpose: Interpersonal competence, a key competence for patient-centered care by nurses, should be understood. Therefore, factors influencing the interpersonal competence of nursing students should be identified to explore and enhance their interpersonal relationships during the undergraduate educational curriculum for nursing educators. In this study factors influencing interpersonal competence, especially on self-assertiveness and empathy in nursing students were identified and analysed. Methods: A cross-sectional study design was used for the study in two Korean nursing colleges with similar baccalaureate nursing curricula. A total of 251 nursing students from freshman to senior year completed a questionnaire to measure related factors that were assumed to influence nursing students' interpersonal competence. Data were collected from October 11 31, 2016. Study variables included self-assertiveness, empathy, interpersonal competence, and socio-demographic status. Multiple regression analysis was used for data analysis. Results: Nursing students' interpersonal competence was explained by personality $(\beta=.22)$, self-assertiveness $(\beta=.16)$ and empathy $(\beta=.38)$. The explanatory power of these predictors was $26.8 \%(p<.001)$. Conclusions: Nursing students' interpersonal competence during the undergraduate nursing years can be enhanced by educational strategies that improve their interpersonal relationship as patient-centered care providers. Simultaneously, the attitude of the nurse educator is also important for nursing students who are to be treated as valuable learners and to improve students' empathy and self-assertiveness ability.
\end{abstract}

Key Words: Assertiveness; Empathy; Interpersonal relations; Nursing students

Received Oct 30, 2021 Revised Jan 18, 2021 Accepted May 13, 2021

Corresponding author: Choi, Jihea https://orcid.org/0000-0003-1881-6342

Department of Nursing, Yonsei University Wonju College of Medicine

20 Ilsan-ro, Wonju 26426, Korea

Tel: +82-33-741-0379, Fax: +82-33-743-9490, E-mail: jiheachoi@yonsei.ac.kr 


\section{INTRODUCTION}

Interpersonal relationships are a complex dynamic process and ongoing interaction between two or more people [1]. Building interpersonal relationships fosters opportunities for high-quality person-centered care in nursing fields [2]. Nursing scholars focusing on human relationships promote mutual trusting relationships between nurses and patients, nurses and health workers, nurses and other involved multidisciplinary care team. If interpersonal relationship is not fundamentally achieved in the nursing environment, achieving the therapeutic effect through nursing care is difficult [3]. In particular, when patients are faced with physical and functional difficulties, are emotionally vulnerable, or require sustained and supportive care in the clinical nursing practice, a well-established therapeutic relationship plays an important role in the patient's recuperation from the disease and regaining their previous health status [2]. Therefore, nursing students' interpersonal competence is an important ability to form interpersonal relationships necessary as future nurses [4].

Peplau's Interpersonal Relations is a theory that explains the importance of interpersonal relationships in nursing education [5]. This theory insisted that nursing students should participate in constructive learning for their growth and personal maturity during the learning process. Nursing students' interpersonal relationships should be developed in a more productive and innovative way, even if they experience frustration and conflict anxiety during the learning process. Nursing students not only learn the communication process in interpersonal relationships during the clinical practicum but also actual communication as an important tool in forming interpersonal relationships [5]. Therefore, the ability to establish satisfactory interpersonal relationships during the nursing curriculum should be prepared by identifying factors influencing nursing students' interpersonal competence.

The twenty-first century is an era of self-assertion and self-expression. In the Korean society, the concept of 'assertiveness' tends to be understood differently from the concept in the West cultural society, that is, 'self-assertion' is regarded as insisting on one's position without considering other party's feelings. Koreans especially tend to focus on etiquette and consideration for their opponents; therefore, they hesitate to speak up undesired or conflicting events [6,7]. However, the social relationship is possibly developed by disclosing more personal information with each other. Avoiding self-assertiveness and lack of understanding about oneself are the great obstacles in building good interpersonal relationships [6,8]. Nurses' self-assertiveness is an important element of nursing activities, so that they can help patients efficiently. Therefore, before pursuing action-oriented nursing, a relationship should be established so that the patient can trust what the nurse presents and exposes regarding his/her problem [9]. Nurses needed to express their own similar experiences and feelings to their co-nurses and doctors, in order to help build intimacy and confidence. In addition, having adequate self-assertiveness can be one of the qualities required in providing quality nursing and performing effective nursing work [10]. Therefore, nurse educators should identify self-assertiveness characteristics of Korean nursing students who are reluctant to assert themselves due to cultural tendencies and describe how self-assertiveness affects the interpersonal skills important for nursing students or the nursing profession.

Empathy is the competency to understand and accept the opponent's position and perspective precisely in the same place as others and is an essential element that should be developed by nurses in order to establish therapeutic relationships with patients and during the clinical practice [11]. The empathic ability facilitates interaction between nurses and patients to form a positive relationship. An effective communication with patients enables the patient and the caregiver to feel satisfied by recognizing patient's desire and solving the problem [12]. Therefore, empathy is an important characteristic that nursing students should have in order to grow as a nursing professional manpower. Moreover, nurse educators in the clinical nursing field must enhance the empathetic component of nursing students and maintain it at a high level from basic nursing education.

The importance of nursing students' interpersonal competence is insufficiently emphasized repeatedly; therefore, its influencing factors have been studied diversely $[4,5]$. However, majority of studies have identified the strong relationship between interpersonal competence and self-assertiveness $[12,13]$ or between interpersonal competence and empathy $[2,11,14]$. No studies have attempted to investigate the relationship among these three variables, interpersonal competence, self-assertiveness, and empathy, especially the effectiveness of self-assertiveness and empathy on the interpersonal competence of nursing students.

Therefore, this study aimed to verify the relationship among self-assertiveness, empathy, and interpersonal competence and the effects of self-assertiveness and empathy on the interpersonal competence of college nursing students. Exploring and enhancing students' interpersonal relationship during the undergraduate educational curriculum can significantly guide how nursing educators can 
teach their students to foster self-assertiveness and emotional empathy in nursing education.

\section{METHODS}

\section{Research Design}

The authors used an exploratory cross-sectional descriptive study design to identify associated factors the interpersonal competence of nursing students focused on self-assertiveness and empathy.

\section{Participants and Data Collection}

The study participants were recruited in two nursing colleges with similar baccalaureate nursing curricula located in W urban city, Korea. Number of study participants were calculated using the $\mathrm{G}^{*}$ Power 3.1.2 package [15], under the condition of linear multiple regression with medium effect size .15[3], an $\alpha$ level of .05, power of .99 and number of predictors of 14 . As a calculation result, at least 251 subjects were required. Therefore, a total of 260 questionnaires (approximately 65 students per grade from freshman to senior) were distributed from October 11 to October 31 2016. Data were collected by six trained research assistants in two nursing colleges. In this study, a total of 251 nursing students (115 participants from A university, 136 participants from B university) participated (96.5\% response rate). Only participants who signed a consent form were allowed to participate in the data collection. The questionnaire response time was approximately 20 minutes. The completed questionnaire was collected in the unmarked envelopes.

\section{Instruments}

A self-administered questionnaire was used to identify the frequency of participant's sociodemographic characteristics (gender, school year, religion, sibling, personality, satisfaction on pocket money, residence with family, grade in college, attendance in communication class, participation in school club, and clinical practicum experience), self-assertiveness, empathy, and interpersonal competence.

\section{1) Self-assertiveness}

Self-assertiveness means an honest expression of one's ideas, such as his or her rights, desires, opinions, thoughts, and feelings, in a language or action, without compromising the rights or feelings of others during an interpersonal interaction [16]. Self-assertiveness was measured using a modified Beon and Kim [16]'s instrument, which was originally developed by Rakos and Schroeder [17] as 'Assertive Behaviour Assessment Scale,' by adapting and evaluating self-assertiveness according to the Korean cultural background. This instrument consists of 20 questions with three subcategories: content (9 items), verbal (7 items), and non-verbal elements (4 items). Responses for each item are rated with a Likert 5-point scale (from 'strongly disagree= 1 ' to 'strongly agree $=5$ '). The authors then converted the total mean score to an item mean to facilitate comparisons with other study variables. Higher scores are more desirable for self-assertive behaviour. In terms of instrument reliability, Cronbach's $\alpha$ in an original study [17] was .80, .76 in a modified version study [16], and .88 in this study.

\section{2) Empathy}

Empathy means understanding the other person's observed experience, as well as an emotional process and ability to perceive it one's own situation from the person's point of view [18]. Empathy was measured using a modified Jeon [19]'s instrument, which was reconstructed from 'Measurement of Emotional Empathy [20]', 'Interpersonal Reactivity Index [18]', and 'Index of Empathy [21]'. This instrument consists of 30 questions with two subcategories: cognitive (15 items) and emotional (15 items) empathy. A Likert 5-point (from 'strongly disagree $=1$ ' to 'strongly agree $=5$ )' was used to rate each item. The authors then converted the total mean score to an item mean to facilitate comparisons with other study variables. Higher scores mean higher level of empathy. In terms of instrument reliability, Cronbach's $\alpha$ in Jeon [19] was .83 and .82 in this study was.

\section{3) Interpersonal competence}

Interpersonal relationships are psychological forms of how a person reacts to another person with a thought or feeling and how to perceive and act on that person. In this study, the authors used the 'Interpersonal Competence Questionnaire' developed by Buhrmester et al. [22] and translated by Kim and Kim [23]. This instrument consists of 40 questions with two subcategories, i.e., initiation (8 items), negative assertion ( 8 items), disclosure ( 8 items), emotional support ( 8 items), and conflict management ( 8 items). The response to each item is rated using a Likert 5-point scale (from 'strongly disagree $=1$ ' to 'strongly agree $=5$ '). The authors then converted the total mean score to an item mean to facilitate comparisons with other study variables. Higher scores indicate proper functioning in interpersonal relationships. In terms of instrument reliability, Cronbach's $\alpha$ in Buhrmester et al. [22] was .83, .82 91 in Kim and Kim [23], and .85 in this study. 


\section{Ethical Consideration}

The study was approved by the institutional review board (IRB) at the authors' institution (CR316041). Participants were informed about the study objectivises, questionnaire contents, data confidentiality and anonymity, and their right to refuse from study participation at any time. Written informed consent was obtained from all participants prior to the start of the study.

\section{Data Analysis}

The collected data were analysed using IBM SPSS/WIN (version 25.0; IBM Corp., Armonk, NY, USA). Statistical significance was judged based on $p<.05$ on both sides. Study variables were analysed as frequency, percentage, mean, and standard deviation. Differences between study variables and interpersonal competence were analysed by independent t-test and one-way ANOVA. Correlations among self-assertiveness, empathy, and interpersonal competence were analysed by Pearson's correlation coefficients. After confirming the appropriateness of the regression model, multiple linear regression analysis was performed to identify influencing factors and explanatory power of interpersonal competence.

\section{RESULTS}

\section{Sociodemographic Characteristics of Nursing Students}

Among nursing students, 221 females $(88.0 \%)$ and 30 male students $(12.0 \%)$ participated, and $21.5 \sim 28.3 \%$ of students participated in each grade. A total of $116(46.2 \%)$ students were religious, 213 (84.9\%) had siblings, 139 (55.4 \%) were introverts, and $112(44.6 \%)$ were extrovert. Student who were satisfied with their pocket money were 128 $(51.0 \%)$, and those who reside with their family were 41 $(16.3 \%)$ only. Perceived own grade in college (GPA) was reported to be low in $33(13.1 \%)$ patients, middle in 174 $(69.3 \%)$, and high in $44(17.5 \%)$. Students who had been attending communication classes during college were 183 $(72.9 \%)$, and those participating in school club recently were 202 (80.5\%). Lastly, half of the participants 123 (49.0\%) had clinical practicum experiences (Table 1).

\section{Self-Assertiveness, Empathy, and Interpersonal Competence of Nursing Students}

Self-assertiveness value ranged from 1.85 to 4.80 out of
Table 1. Sociodemographic Characteristics of Nursing Students $(N=251)$

\begin{tabular}{|c|c|c|}
\hline Variables & Categories & $\mathrm{n}(\%)$ \\
\hline \multirow[t]{2}{*}{ Gender } & Male & $30(12.0)$ \\
\hline & Female & $221(88.0)$ \\
\hline \multirow[t]{4}{*}{ School year } & First & $66(26.3)$ \\
\hline & Second & $60(23.9)$ \\
\hline & Third & $54(21.5)$ \\
\hline & Fourth & $71(28.3)$ \\
\hline \multirow[t]{2}{*}{ Religion } & No & 135 (53.8) \\
\hline & Yes & $116(46.2)$ \\
\hline \multirow[t]{2}{*}{ Siblings } & No & 38 (15.1) \\
\hline & Yes & $213(84.9)$ \\
\hline \multirow[t]{2}{*}{ Personality } & Introvert & $139(55.4)$ \\
\hline & Extrovert & $112(44.6)$ \\
\hline \multirow{2}{*}{$\begin{array}{l}\text { Satisfaction with pocket } \\
\text { money }\end{array}$} & No & $123(49.0)$ \\
\hline & Yes & $128(51.0)$ \\
\hline \multirow[t]{2}{*}{ Residence with family } & No & $210(83.7)$ \\
\hline & Yes & $41(16.3)$ \\
\hline \multirow[t]{3}{*}{ Grade in college (GPA) } & Low & $33(13.1)$ \\
\hline & Middle & $174(69.3)$ \\
\hline & High & $44(17.5)$ \\
\hline \multirow{2}{*}{$\begin{array}{l}\text { Attended communication } \\
\text { class }\end{array}$} & No & $68(27.1)$ \\
\hline & Yes & $183(72.9)$ \\
\hline \multirow[t]{2}{*}{ Participating school club } & No & 49 (19.5) \\
\hline & Yes & $202(80.5)$ \\
\hline \multirow{2}{*}{$\begin{array}{l}\text { Have had clinical practicum } \\
\text { experience }\end{array}$} & No & $128(51.0)$ \\
\hline & Yes & $123(49.0)$ \\
\hline
\end{tabular}

5 , with a mean score of $3.74 \pm 0.53$. As subcategories of self-assertiveness, the mean value of content expression was $3.52 \pm 0.48$, verbal expression $3.82 \pm 0.74$, and body expression $4.08 \pm 0.75$. Empathy value ranged from 2.00 to 4.43 out of 5 , with a mean score of $3.49 \pm 0.35$. As regards the subcategories of empathy, the mean value of cognitive empathy was $3.46 \pm 0.36$ and emotional empathy was 3.51 \pm 0.41 . Interpersonal competence value ranged from 1.18 to 4.30 out of 5 , with a mean score of $3.51 \pm 0.32$. As subcategories of interpersonal competence, the mean value of initiation expression was $3.49 \pm 0.39$, negative assertion $3.39 \pm 0.50$, disclosure $3.41 \pm 0.46$, emotional support $3.85 \pm$ 0.51 , and conflict management $3.40 \pm 0.37$ (Table 2).

\section{Interpersonal Competence according to Socio- demographic Characteristics of Nursing Stu- dents}

Interpersonal competence was significantly different according to personality ( $\mathrm{t}=-5.46, p<.001): 3.41 \pm 0.32$ for introvert and $3.62 \pm 0.28$ for extrovert personalities. How- 
Table 2. Self-Assertiveness, Empathy, and Interpersonal Competence of Nursing Students $(N=251)$

\begin{tabular}{lccc}
\hline Variables & Item $\mathrm{M} \pm \mathrm{SD}$ & Min. & Max. \\
\hline Self-assertiveness & $3.74 \pm 0.53$ & 1.85 & 4.80 \\
$\quad$ Content expression & $3.52 \pm 0.48$ & 2.11 & 4.67 \\
$\quad$ Verbal expression & $3.82 \pm 0.74$ & 1.57 & 5.00 \\
$\quad$ Body expression & $4.08 \pm 0.75$ & 1.25 & 5.00 \\
Empathy & $3.49 \pm 0.35$ & 2.00 & 4.43 \\
$\quad$ Cognitive empathy & $3.46 \pm 0.36$ & 2.27 & 4.53 \\
$\quad$ Emotional empathy & $3.51 \pm 0.41$ & 1.73 & 4.40 \\
Interpersonal competence & $3.51 \pm 0.32$ & 1.18 & 4.30 \\
$\quad$ Initiation & $3.49 \pm 0.39$ & 1.13 & 4.63 \\
$\quad$ Negative assertion & $3.39 \pm 0.50$ & 1.25 & 4.63 \\
Disclosure & $3.41 \pm 0.46$ & 1.50 & 4.75 \\
Emotional support & $3.85 \pm 0.51$ & 1.00 & 5.00 \\
Conflict management & $3.40 \pm 0.37$ & 1.00 & 4.63 \\
\hline
\end{tabular}

Max.=Maximum; Min. $=$ Minimum.

ever, other variables except personality were not significantly different (Table 3).

\section{Correlation among Self-Assertiveness, Empathy, and Interpersonal Competence of Nursing Stu- dents}

Interpersonal competence was significantly positively correlated with self-assertiveness $(\mathrm{r}=.26, p<.001)$ and empathy $(\mathrm{r}=.42, p<.001)$. However, self-assertiveness was not significantly correlated with empathy (Table 4).

\section{Effects of Self-Assertiveness and Empathy on the Interpersonal Competence of Nursing Stu- dents}

To identify the effects of self-assertiveness and empathy on interpersonal competence, multiple linear regression was conducted. Personality, which was significantly different based on sociodemographic variables, was input as control variable in this regression analysis. For evaluation of the assumptions, the tolerance limit of independent variables was .93, which was larger than 0.1 , and the variance inflation factor (VIF) was 1.08, indicating no multi-collinearity. The Durbin-Watson statistic was 2.02, which was close to 2.0, suggesting no autocorrelation among independent variables. As a result of confirming the scatter plot of the dependent variable through the normal P-P plot, the shape of the residual was uniformly distributed, confirming the normality of the residual. It was also confirmed that there were no outliers as the Cook distance was less than 1 from the minimum of .001 to the maximum
Table 3. Interpersonal Competence according to Sociodemographic Characteristics of Nursing Students

$(N=251)$

\begin{tabular}{|c|c|c|c|}
\hline \multirow[t]{2}{*}{ Variables } & \multirow[t]{2}{*}{ Categories } & \multicolumn{2}{|c|}{$\begin{array}{l}\text { Interpersonal } \\
\text { Competence }\end{array}$} \\
\hline & & $\mathrm{M} \pm \mathrm{SD}$ & t or $F(p)$ \\
\hline \multirow[t]{2}{*}{ Gender } & Male & $3.54 \pm 0.26$ & 0.58 \\
\hline & Female & $3.50 \pm 0.33$ & $(.560)$ \\
\hline \multirow[t]{4}{*}{ School year } & First & $3.53 \pm 0.28$ & 2.38 \\
\hline & Second & $3.49 \pm 0.28$ & $(.070)$ \\
\hline & Third & $3.42 \pm 0.41$ & \\
\hline & Fourth & $3.57 \pm 0.31$ & \\
\hline \multirow[t]{2}{*}{ Religion } & No & $3.52 \pm 0.28$ & 0.35 \\
\hline & Yes & $3.50 \pm 0.36$ & $(.729)$ \\
\hline \multirow[t]{2}{*}{ Sibling } & No & $3.51 \pm 0.30$ & 0.16 \\
\hline & Yes & $3.51 \pm 0.33$ & $(.876)$ \\
\hline \multirow[t]{2}{*}{ Personality } & Introvert & $3.41 \pm 0.32$ & -5.46 \\
\hline & Extrovert & $3.62 \pm 0.28$ & $(<.001)$ \\
\hline \multirow{2}{*}{$\begin{array}{l}\text { Satisfaction with } \\
\text { pocket money }\end{array}$} & No & $3.48 \pm 0.29$ & -1.22 \\
\hline & Yes & $3.53 \pm 0.35$ & $(.223)$ \\
\hline \multirow[t]{2}{*}{ Residence with family } & No & $3.50 \pm 0.33$ & -0.30 \\
\hline & Yes & $3.52 \pm 0.27$ & $(.765)$ \\
\hline \multirow{3}{*}{$\begin{array}{l}\text { Grade in college } \\
\text { (GPA) }\end{array}$} & Low & $3.45 \pm 0.26$ & 0.64 \\
\hline & Middle & $3.51 \pm 0.34$ & $(.526)$ \\
\hline & High & $3.53 \pm 0.30$ & \\
\hline \multirow{2}{*}{$\begin{array}{l}\text { Attended } \\
\text { communication class }\end{array}$} & No & $3.51 \pm 0.28$ & 0.618 \\
\hline & Yes & $3.51 \pm 0.36$ & $(.537)$ \\
\hline \multirow{2}{*}{$\begin{array}{l}\text { Participating in } \\
\text { school club }\end{array}$} & No & $3.58 \pm 0.34$ & 1.84 \\
\hline & Yes & $3.49 \pm 0.32$ & $(.066)$ \\
\hline \multirow{2}{*}{$\begin{array}{l}\text { Have had clinical } \\
\text { practicum experience }\end{array}$} & No & $3.53 \pm 0.27$ & 0.06 \\
\hline & Yes & $3.50 \pm 0.33$ & $(.951)$ \\
\hline
\end{tabular}

Table 4. Correlation among Self-Assertiveness, Empathy, and Interpersonal Competence of Nursing Students $(N=251)$

\begin{tabular}{lccc}
\hline \multirow{2}{*}{ Variables } & Empathy & & $\begin{array}{c}\text { Interpersonal } \\
\text { competence }\end{array}$ \\
\cline { 2 - 2 } Self-assertiveness & $\mathrm{r}(p)$ & & $\mathrm{r}(p)$ \\
\hline Empathy & $.07(.257)$ & & $.26(<.001)$ \\
\hline
\end{tabular}

of .947 , and the standardized residual values were distributed between -2 and 2 , confirming the equality of variance.

The final regression model (Model 2) showed that personality $(\beta=.22, p<.001)$, self-assertiveness $(\beta=.16, p=.004)$ and empathy $(\beta=.38, p<.001)$ explained $26.8 \%$ of interpersonal competence of nursing students $(\mathrm{F}=31.58, p<.001)$ (Table 5). 
Table 5. Effects of Self-Assertiveness and Empathy to Interpersonal Competence of Nursing Students

\begin{tabular}{|c|c|c|c|c|c|c|c|c|c|c|}
\hline \multirow{2}{*}{ Variables } & \multicolumn{5}{|c|}{ Model 1} & \multicolumn{5}{|c|}{ Model 2} \\
\hline & B & SE & $\beta$ & $\mathrm{t}$ & $p$ & B & $\mathrm{SE}$ & $\beta$ & $t$ & $p$ \\
\hline (Constant) & 3.41 & 0.26 & & 132.05 & $<.001$ & 1.84 & 0.21 & & 8.66 & $<.001$ \\
\hline Personality $^{\dagger}$ & 0.21 & 0.04 & .33 & 5.46 & $<.001$ & 0.14 & 0.04 & .22 & 3.89 & $<.001$ \\
\hline Self-assertiveness & & & & & & 0.10 & 0.04 & .16 & 2.87 & .004 \\
\hline Empathy & & & & & & 0.35 & 0.05 & .38 & 6.92 & $<.001$ \\
\hline
\end{tabular}

${ }^{\dagger}$ Dummy variable: Personality ( $0=$ Introvert, $1=$ Extrovert).

\section{DISCUSSION}

Establishing a successful interpersonal relationship is the most important challenge for nurses not only with patients who need quality nursing care but also with colleagues who work with them. Nurses with successful interpersonal competence induce patient-centered care to maintain safety in providing effective nursing care [24]. Recognizing how interpersonal relationship can affect patient safety is an important first step in improving the quality of patient care [25]. Majority of nursing education curriculum focuses on the scientific basis of nursing and providing nursing skills, and only theoretical concepts are dealt inside the classroom about the interpersonal relationship, therapeutic communication, or concepts of empathy toward patients [26]. However, these concepts are usually learned and practiced through clinical practicum hours rather than in classes. Nursing educators should understand key variables that affect nursing students to improve interpersonal competencies and how they can approach to improve competencies required when nursing students deal with patients in clinical practice within the nursing major curriculum.

According to the final result of this study, nursing students' interpersonal competence was explained by empathy, personality, and self-assertiveness. First of all, interpersonal competence in this study population was 3.51 out of 5 from freshman to senior. This value is slightly lower than 3.65 in 231 Korean nursing and medical students from junior to senior [27]. However, it was similar to 3.58 in 1,209 college students from freshman to senior taking psychology courses at south western university in America [28], conducted in the same school year with this study population. In particular, senior students had the highest interpersonal competence scores, the same as in other comparative studies $[27,28]$. This can be due to the increase in the interpersonal competence as the experience of forming relationships with various patients increases as seniors accumulate clinical practice experience. However, the differ- ence in interpersonal competency scores was not statistically significant according to school years in this study. Therefore, further studies comparing the differences in competences after securing a sufficient number of participants from freshman to senior years should be conducted.

In addition, among the subcategories of interpersonal competence (initiation, negative assertion, disclosure, emotional support, and conflict management), the value of emotional support showed the highest score in this study and other two comparative studies [27,28]. 'Negative assertion' had the lowest score in this and Je et al. [27]'s studies on Korean nursing and medical students, whereas 'disclosure' had the lowest score in Dunn [28]'s study in the USA. These results can be understood as a result of cultural characteristics of Koreans who do not express their opinions in front of others with different opinions [6]. However, based on the results found in this study, self-assertion is a major variable affecting the interpersonal competence of Korean nursing students. In a complex healthcare environment, a cooperative relationship should be established through accurate communication, and self-expression with colleagues from various disciplines surrounding the nurses will not only maintain patient's health who is the target of nursing but also bring the best practical outcomes [29]. Therefore, in the global era, nursing educators should become aware of their students' different characters according to their ethnic or culture in order to train and educate them accordingly so that they can express their opinions effectively.

As a variable affecting the interpersonal competence of college nursing students, the mean value of empathy in this study was similar to the scores in other studies [14]. Empathy is essential for clinical and educational practice and human resource management, combining scientific knowledge with interpersonal relationships in professional-patient-focused nursing practice, health-disease processes, technical skills development, and balance among all branches [11]. The results of this study demonstrated that empathy was positively correlated with interpersonal 
competency, and the important influence of empathy on the formation of successful interpersonal relationship was reconfirmed. The nursing educator's efforts to improve empathy can be proven by studies showing that it is improved through practicum class using simulation teaching methods [30]. These efforts are expected to have a significant impact on enabling nurse-patient interpersonal relationships, which Peplau [5] emphasized in nursing education, i.e., during the clinical practicum of nursing students.

As another affecting variable, the mean value of interpersonal competence in nursing students with an extrovert personality was significantly higher than those with an introvert personality in this study. This can be understood in the same manner as the result of correlation analysis between variables in which students with high self-assertiveness scores also had high interpersonal competence. These results are similar to those of researchers who insist that nurses' self-assertive and interpersonal relationship abilities should be equally well established in order to form an emotional intelligence to become qualified clinical nurses and nurse leaders [8]. Therefore, nursing educators should recognize that the self-assertiveness of nursing students plays an important role in the formation of a successful interpersonal relationship between the nurse and patient or the nurse and other professionals in clinical practice and they should be able to identify students' personality first to improve their self-assertiveness.

As the last affecting variable, self-assertion which was the ability to assert one's opinions and to empathize with others confirmed the important role of nursing students' interpersonal relationships. Even if self-assertion is not culturally acceptable [6,7], nursing practice education can still produce the best nursing outcomes and maintain the best safety of patients by providing training to develop effective self-assertive skills while improving empathy. This effort will be an important educational element for nursing educators to nurture prospective nurses who can form successful nurse-patient and nurse-other professionals' relationships.

There are some limitatios of this study. This study was conducted only in two nursing colleges in Korea, therefore it is limited in explaining the interpersonal competence of nursing students of the Korean nursing students. When generalizing the current results to other cultural groups should be careful. In addition, this study focused only on self-assertiveness and empathy to interpersonal competence although many diverse variables affect; therefore, it is limited in explaining general nursing students' interpersonal competence. Further studies are needed to explore nursing students' interpersonal competence with more diverse factors.

\section{CONCLUSION}

Establishing a successful interpersonal relationship is the most important challenge for nurses. This study was conducted to identify factors influencing the interpersonal competence of Korean nursing students, especially on selfassertiveness and empathy. Based on the results, nursing students' interpersonal competence was affected by personality, self-assertiveness, and empathy in this study, and the explanatory power of personality, self-assertiveness and empathy on the interpersonal competence was $26.8 \%$. Nursing educators should recognize that nursing students' self-assertiveness and empathy play an important role in enhancing their successful interpersonal competence. Further, nursing students' interpersonal competence during the undergraduate nursing curriculum will be possibly enhanced by educational strategies that improve their self-assertiveness and empathy.

\section{ACKNOWLEDGMENTS}

The authors express their deep appreciation to the students and nursing faculties who agreed to participate in data collection at nursing colleges for this study.

\section{CONFLICTS OF INTEREST}

The authors declared no conflict of interest.

\section{REFERENCES}

1. Piao MH, Kang MJ, Park CS. Relationship between the interpersonal disposition and interactive characteristics of nursing college students: a social network analysis. Korean ParentChild Health Journal. 2016;19(1):25-32.

2. Schwind JK, Beanlands H, Lapum J, Romaniuk D, Fredericks $\mathrm{S}$, LeGrow K, et al. Fostering person-centered care among nursing students: creative pedagogical approaches to developing personal knowing. Journal of Nursing Education. 2014;53(6): 343-347. https://doi.org/10.3928/01484834-20140520-01

3. Chung MS. Relations on self-esteem, empathy and interpersonal relationship for reinforcing competence in communication of nursing students. The Journal of Korean Academic Society of Nursing Education. 2014;20(2):332-340.

https://doi.org/10.5977/jkasne.2014.20.2.332

4. Satu KU, Leena S, Mikko S, Riitta S, Helena LK. Competence areas of nursing students in Europe. Nurse Education Today. 2013;33(6):625-632.

https://doi.org/10.1016/j.nedt.2013.01.017

5. Peplau HE. Peplau's theory of interpersonal relations. Nursing 
Science Quarterly. 1997;10(4):162-167.

https://doi.org/10.1177/089431849701000407

6. Park SH, Kim JE, Bang BR. A study on the effects to the communication capability and the accommodation of other person's perspective for the self understanding, the self accommodation and the self communication-centered on the university students in Gungji-do and Seoul. The Journal of the Korea Contents Association. 2016;16(7):410-422. https://doi.org/10.5392/JKCA.2016.16.07.410

7. Aoki SK, Mearns J, Robinson Kurpius SE. Social anxiety and assertiveness: The role of self-beliefs in Asian Americans and European Americans. Journal of Mental Health Counseling. 2017;39(3):263-274. https://doi.org/10.17744/mehc.39.3.06

8. Coladonato AR, Manning ML. Nurse leader emotional intelligence: how does it affect clinical nurse job satisfaction? Nursing Management. 2017;48(9):26-32. https://doi.org/10.1097/01.NUMA.0000522174.00393.f2

9. Jung SW, Hwang RI, Lee YS. Satisfaction to college life and stress of clinical practice among nursing students. Journal of the Korea Convergence Society. 2017;8(4):265-272.

https://doi.org/10.15207/JKCS.2017.8.4.265

10. Steuber P, Pollard C. Building a therapeutic relationship: How much is too much self-disclosure? International Journal of Caring Sciences. 2018;11(2):651-657.

11. Yeo HJ. Predictors of empathy for nursing students. Journal of the Korea Academic-Industrial cooperation Society. 2017;18 (1):177-184. https://doi.org/10.5762/KAIS.2017.18.1.177

12. Shen Z. Cultural competence models and cultural competence assessment instruments in nursing: a literature review. Journal of Transcultural Nursing. 2015;26(3):308-321. https://doi.org/10.1177/1043659614524790

13. Sun FK, Long A, Tseng YS, Huang HM, You JH, Chiang CY. Undergraduate student nurses' lived experiences of anxiety during their first clinical practicum: a phenomenological study. Nurse Education Today. 2016;37:21-26. https://doi.org/10.1016/j.nedt.2015.11.001

14. Kim H, Yi M. Factors influencing empathy in nursing students in Korea. Journal of Korean Academic Society of Nursing Education. 2015;21(2):237-245. https://doi.org/10.5977/jkasne.2015.21.2.237

15. Faul F, Erdfelder E, Buchner A, Lang AG. Statistical power analyses using $G^{*}$ Power 3.1: tests for correlation and regression analyses. Behavior Research Methods. 2009;41(4):1149-1160. https://doi.org/10.3758/BRM.41.4.1149

16. Beon CJ, Kim SH. Assertion training program. Student Guidance Research. 1980;13:51-85.

17. Rakos RF, Schroeder HE. Self-directed assertiveness training. New York, NY: Bio Monitoring Application; 1980. p. 215-247.

18. Davis MH. Measuring individual differences in empathy: Evidence for a multidimensional approach. Journal of Personality and Social Psychology. 1983;44(1):113-126.

https://doi.org/10.1037/0022-3514.44.1.113

19. Jeon BS. The relationship between empathy and altruistic behavior [master's thesis]. Daejeon, Korea: Choongnam National University; 2003.

20. Mehrabian A, Epstein N. A measure of emotional empathy. Journal of Personality. 1972;40(4):525-543. https://doi.org/10.1111/j.1467-6494.1972.tb00078.x

21. Bryant BK. An index of empathy for children and adolescents. Child Development. 1982;53(2):413-425. https://doi.org/10.2307/1128984

22. Buhrmester D, Furman W, Wittenberg MT, Reis HT. Five domains of interpersonal competence in peer relationships. Journal of Personality and Social Psychology. 1988;55(6):991-1008. https://doi.org/10.1037//0022-3514.55.6.991

23. Kim GD, Kim SI. A study on the effect of group counseling program for improvement of interpersonal competence. Seoul National University Student Life Research Institute. 1999;35 (1):83-95.

24. Albagawi B. Emotional intelligence among the fourth year nursing students: a cross-sectional study. Advances in Social Sciences Research Journal. 2018;5(11):561-569.

https://doi.org/10.14738/assrj.511.5732

25. Lee CT, Doran DM. The role of interpersonal relations in healthcare team communication and patient safety: a proposed model of interpersonal process in teamwork. Canadian Journal of Nursing Research. 2017;49(2):75-93. https://doi.org/10.1177/0844562117699349

26. Deane WH, Fain JA. Incorporating Peplau's theory of interpersonal relations to promote holistic communication between older adults and nursing students. Journal of Holistic Nursing. 2016;34(1):35-43. https://doi.org/10.1177/0898010115577975

27. Je NJ, Park MR, Hwa JS. Effects of college students' adjustment, character, and communication competence on field practice adaptation-mediating effect of interpersonal competence. Journal of Digital Convergence. 2019;17(9):249-258. https://doi.org/10.14400/JDC.2019.17.9.249

28. Dunn TW. A test of associations among generalized attachment, interpersonal competence, relational self-construal and happiness among undergraduates [dissertation]. Lubbock, TX: Texas Technoligy University; 2018.

29. Rosenstein A, Stark D. Emotional Intelligence: a critical tool to understand and improve behaviors that impact patient care. Journal of Psychology and Clinical Psychiatry. 2015;2(1):00066. https://doi.org/10.15406/jpcpy.2015.02.00066

30. Bas-Sarmiento P, Fernandez-Gutierrez M, Diaz-Rodriguez M, Carnicer-Fuentes C, Castro-Yuste C, García-Cabanillas MJ, et al. Teaching empathy to nursing students: a randomised controlled trial. Nurse Education Today. 2019;80:40-51. https://doi.org/10.1016/j.nedt.2019.06.002 